Antônio Houaiss, filólogo, é Antônio Houaiss membro da Academia Brasileira de Letras.

\title{
A Linguagem oficial
}

PROPOSTA - Tanto no magistério, quanto na pesquisa lingüística (e, quando se confessa a si mesma, na filológica), quanto na opinião pública que se crê titulada para pronunciar-se a tal respeito, nela incluídos escritores, magistrados, jornalistas, comunicólogos, profissionais da palavra, há, no Brasil, certo consenso em que o estado da língua, escrita ou falada, é, nesta nossa contemporaneidade, algo que deixa tanto a desejar, que chamar caóticos aos usos que se vêm fazendo da língua é quase eufemismo.

Proponho-me aqui tentar alinhar algumas das razões que militariam para aquela impressão, alinhando, em seguida, algumas sugestões que possam, talvez, quer esclarecer aspectos relevantes da questão, quer encaminhar um melhor tratamento social da mesma, quando haja uma didática a ser preconizada. Como tudo aqui é opinião pessoal que não engaja a de ninguém, seria bom, creio, que, subseqüentemente, outros, mais titulados do que eu e se possível em linguagem menos obscura que a minha, se pronunciassem a respeito, pois é de crer que em breve futuro algumas decisões normativas se venham a aconselhar, razão por que um debate desse tipo só poderá ser salutar.

UM POUCO DO PASSADO - O presente é quase sempre mais compreensível quando se possa buscar suas raízes verossímeis ou certas no passado. E em matéria social de língua, isso parece fundamental, como se verá.

A nossa língua, o português, se impôs ao nosso meio, tornando-se língua nacional dos brasileiros, nosso idioma nacional, isto é, não apenas nossa língua comum e nossa língua de cultura, senão que também nosso vernáculo, vale dizer, a língua que se aprende no seio da família (o que é verdade para um altíssimo percentual de nossa população). A rigor, sem estraçalhamentos nominalistas, nada impede que lhe chamemos idioma brasileiro. $\dot{E}$ de importância capital reconhecer, porém, que, se não somos um país unilíngüe, pois temos centenas de línguas ainda faladas pelos 100 mil índios supérstites (o que lhes dá uma média inferior a mil usuários por língua, espelho de seu desaparecimento cultural, já 
que essa média supõe casos de pouco mais ou menos 50 indivíduos, apenas, falantes de certas línguas) e, sem dúvida, um contigente de várias colônias (italiano, espanhol, alemão, russo, ucraniano, polaco, japonês, árabes...); repitamos: se nã́o somos um país unilingüe, somos de um plurilingüismo todo especial, em que as "outras" línguas parecem realmente ter um estatuto secundário provisório em vias de assimilação (não discuto o mérito desse processo). E, aí quase sem dúvida, para todas essas populações alofônicas a segunda língua é sempre o português, o que fortalece seu estatuto de língua comum sob quaisquer aspectos, inclusive, nesses casos, de veicular.

A situação linguageira do Brasil presente derivou de uma profunda e intensa luta glotofágica e etnocida, pois o português "venceu" comendo línguas e matando culturas - e o português já era, na imensa parte do processo, a língua dos "brasileiros". De fato, nos três primeiros séculos de ocidentalização do Brasil, foi ele palco dessas lutas, que subsistem nos seus estertores, ao que parece, finais, pois é improbabilíssimo que vivam sem aculturação, e aculturação significará, cedo ou tarde, a perda de sua língua e cultura originais.

A absorção das muitas línguas e falares africanos que foi aqui praticada desde o início, objeto que foi de uma política quase-consciente, de que a prática do tráfico, nos mercados daqui, foi decisiva e segura: separar pais de filhos, maridos de mulheres, irmãos de irmãs, por famílias e, sempre que possivvel, por línguas. Se não se magnificam os resíduos presentes, não há como negar o caráter evanescente desses resíduos de línguas e falares africanos no Brasil, ainda que de alto valor documental para um estado de coisas passadas.

DADOS QUANTITATIVOS - A partir dos inícios do século XIX, quando nossa população seria em torno de 3 milhões de habitantes, o português ia assumindo a posição de língua majoritária, tanto absolutamente (isto é, sobre os 3 milhões referidos), como relativamente (isto é, nas principais áreas "civilizadas" Pará-Belém, Bahia-Salvador, Rio de Janeiro, São Paulo, Minas Gerais...). Essa supremacia foi-se ampliando e consolidando, de tal arte que, por 1920, quando seríamos 20 milhões de habitantes, tudo o mais - indigenato, africanato e coloniato, em estado de ilhamento linguageiro próprio - era já relativamente secundário em termos numéricos.

No Brasil, a língua na sua modalidade escrita foi sempre e só a portuguesa, quer antes da decisão oficial, quer, com Pombal, depois: a concorrência do latim, dos jesuítas e eclesiásticos outros, de um lado, a do francês, espanhol, holandês (ou flamengo), de outro, assim como a do alemão, do russo, do polaco, do italiano, do japonês, por fim, não altera a afirmativa em sua essência. Nessa altura de 1920, nossa população teria um índice máximo, digamos, de $20 \%$ de alfabetizados: sabiam ler (mas poucos escreveriam, além da assinatura) algo como 4 milhões de habitantes do país, o que, apesar das aparências, era um progresso imenso, comparado com o que ocorreria por 1820 , isto é, um século antes, quando já seríamos 3,5 milhőes de habitantes. Na melhor das hi- 
póteses, não há razão para crer que houvesse então mais que $0,5 \%$ de literatados, seja, cerca de 18 mil pessoas.

Entre esses dois limites temporais - 1820 e 1920 - , a modalidade escrita (e a "lida" em público, que não é propriamente a falada) foi usada para fins oficiais, práticos, sentimentais e estéticos (por exemplo, para a redação e edição de leis e conexas, para a correspondência e contabilidade comerciais e burocráticas, para a relação entre parentes e amigos e enamorados, para a poesia e o teatro e a ficção), mas usada por uma minoria mesmo, se levados em conta os índices de alfabetização, os presumíveis índices de leitura pelo prazer de ler (sempre muitíssimo mais baixos do que os anteriores) e os presumíveis índices de escritura (vá lá o termo, sempre menores que os anteriores).

COMO ERA VISTA A LINGUA - Durante esse lapso de tempo, a língua foi "vista", ideologicamente, de três (pelo menos) modos pelos próprios usuários: como portuguesa e dos portugueses (devendo, por isso, os usuários de outras origens que não portuguesas subordinar-se passivamente aos ditames dos "proprietários" da língua), como portuguesa e também dos brasileiros (que não só deveriam "aprender" os padrões dos portugueses, mas freqüentemente foram ferrenhos defensores desses padrōes e da casticidade dessa língua de "adoção") e como portuguesa e/ou brasileira e/ou angolana e/ou maçambiquense e/ou etc. isto é, bem comum que será tanto mais meu quanto mais for de todos, admitindo, como bem comum, variaçð̃es, que vão desde as variedades nacionais, até as regionais, locais - na horizontalidade -, profissionais, etárias, individuais - na verticalidade - , e de registros - formais, informais, emocionais, sentimentais, blasfemos, piedosos etc. ("dentro" de cada indivíduo falante ou escrevente): em suma, a variedade na unidade, a unidade na variedade.

O LITERARIO - Se, ideologicamente, ela foi "vista" daqueles modos, na prática houve no Brasil um processo literário de aproximação do escrito ao falado e influência do escrito no falado, a saber, uma interinfluência entre essas duas modalidades principais (pois é óbvio que há interinfluência entre todos os tipos de segmentação sobre todos os tipos numa dada área de contatos numa dialética permanente de diferenciação-unificação instauradora da variedade na unidade e unidade na variedade).

Se se excluem "nossos" escritores dos séculos XVI e XVII, porque realmente não são nossos, Gregório de Matos vai ser sobretudo na sua musa satírica e na fescenina - o primeiro trovador de linguagem normal (de transmissão oral) com traços daquela aproximação: uma cultura literária portuguesa que "quis" de fato ser expressão de um protesto de brasileiros, identificando-se com estes talvez até no repontar de sua dialetação. E daí pela frente, saltando os árcades mineiros de maioria profundamente lusitanizante na linguagem, a verdade é que o nosso neoclassicismo e o nosso romantismo - tanto o da chamada primeira quanto o da chamada segunda geração - demonstraram à saciedade uma série de brechas brasileirizantes na linguagem lusitana tradicional. So a partir do realismo e sobretudo do parnasianismo é que a criação literária brasileira passa a inclinar-se à canônica gramatical colocada em camisa-de-força. 
Que se passara? Passara-se algo de notável: o primeiro grande lexicógrafo moderno da língua é um carioca, Antônio de Morais Silva, pelos inícios do século XIX (1813); frei Caneca (17791825) é talvez o primeiro gramático brasileiro, inaugurando uma série enorme de nomes altamente prestigiosos como zeladores da língua e normalizadores da mesma, cujos frutos se patenteiam quando intermediou o tempo necessário. A canônica gramatical em causa criou famosos cavalos de batalha de desclassificação ética, cultural, estética e o mais, com um pronome átono "mal" colocado, com uma regência "errada", com um sujeito de reduzida deslocado, com neologismo morfológico híbrido, com neossemia afrancesada, com barbarismos de quaisquer fontes. Essa gramática e esses gramáticos - de zelo e competência incontestáveis, mas de visão parada em "defesa" e "ilustração" da "nossa" língua - só se abonavam em autores portugueses, em escritos portugueses, em exemplos portugueses. Somente na década de 1920-1930 é que nossos gramáticos e filólogos ousam começar a exemplificar com textos de brasileiros (é bem verdade que quando esses textos corroboram os textos portugueses...). João Ribeiro (1860-1934), no plano ensaístico, e Sousa da Silveira (1883-1967), no didático, são as vozes que, timidamente, primeiro se alçam em favor da linguagem tal como praticada por escritores brasileiros.

O nosso romantismo - sobretudo quando editorado aqui, isto é, tipograficamente composto e impresso entre nós - tendeu, de fato, a aceitar progressivamente o que poderíamos chamar de características de nossa variedade. Mas os livros subseqüentemente impressos em Portugal e na França passam a revelar uma suspeitíssima casticidade. Pesquisas recentes de Afrânio Coutinho, e num texto já "tardio", pois do eminente Raul Pompéia, deixam patente que se trata de casticismo de ... revisores portugueses - e essa suspeita parece (redimindo a pobre Carolina) caber até para com textos de Machado de Assis.

A onda de gramáticas, gramáticos e consultórios gramaticais pela imprensa que policiou o português escrito no Brasil foi apoiada por um magistério prestigioso, igualmente purista e casticista, muito mais categorizado socialmente e muito mais eficaz (número de aulas e horários semanais maiores, número de alunos por classe menor, número total de estudantes baixo - fonte de elitismo), o que fez do escrever bem um dos títulos de honra e de acesso no cursus honorum de entre, digamos, 1880-1950, mesmo depois dos ruídos e barulhos crescentes da Semana de Árte Moderna de São Paulo (1922). Na literatura, especificamente, a operação era de fato exeqüível, se se leva em conta que o número de escritores era baixo e mais baixo o de leitores. Se hoje ainda não superamos a casa de 1 livro/per capita/per annum, não será de estranhar que por aqueles idos fosse de meio ou um terço ou mesmo de um quarto de livro. Afinal, raros seriam (e ousariam manifestá-lo? sim! um Lima Barreto, por exemplo) os que não estavam catequizados da noção da norma normalizadora (e fossilizadora). Formas de fugir a isso para não incidir em total falsidade foram escritos em que os diálogos eram reduzidos a quase nada, a fim de que não se fosse obrigado a pôr o pronominho correto na boca da mucama negra. A genialidade de Machado, a tal respeito, levou à estupenda solução do estilo indireto aparente. 
O INICIO DO "CAOS" - De 1920 para cá, algumas tendências começaram a patentear-se aos olhos de todos os brasileiros, muitos dos quais (a maioria, talvez, no início) furiosamente alarmados:

a) a criação literária começou a dirigir-se a mil e uns temas com mil e uns problemas em mil e umas situaçð̃es sociais e, ipso facto, linguageiras - de modo que o objeto artístico procurado pelo criador começou a determinar-lhe os usos que faria da linguagem e da língua portuguesa/brasileira - uso racional, dialético, documental, emocional, local, onírico, demencial etc. etc. etc. - e como, nessas condiçð̋es, "respeitar" uma canônica gramatical do correto lógico-tradicional?;

b) a democratização com massificação do ensino foi intensificada a partir de então, com crescimento ponderável recente e todo um cortejo de problemas conexos. Conseqüente da proletarização da condição de professor, do engurgitamento dos currículos e, em particular, da redução do número de horas e de aulas do estudo escolarizado da língua tornada "comunicação e expressão", em que a transmissão institucionalizada de uma língua de cultura, que se tem de estudar muito e por muito tempo, fica num desvão do ensino; conseqüente disso tudo foi o patentear-se à tona da evidência a impotência coletiva, nacional, de respeitar os cânones gramaticais (sem discutir sua legitimidade), impotência coonestada, aparentemente, pelos principais e maiores usuários da língua - os poetas, os ficcionistas, os teatrólogos, os dramaturgos, a darem a impressão de que a tratavam por paus e por pedras;

c) a progressiva presença da amostragem dos meios de comunicação social de massa - tanto gráfica quanto eletrônica trouxe à evidência e à audiência os variadíssimos usos e padrões e subnormas de segmentos orais, colocando a linguagem "lida", isto é, previamente escrita, numa posição quantitativamente quase desprezivel.

CODIFICAR A NORMA? - Para muitos espíritos, tudo isso é o retrato ou reflexo de um mau estado social de coisas, que gera e é gerado pelo mesmo vício social. A língua ter-se-ia degradado, porque a teríamos degradado, e a teríamos degradado porque houve fatos externos que militaram para isso.

Caberia, assim, ver se nos interstícios desse tecido aparentemente canceroso não haveria alguns sintomas de saúde, presente e futura, que pudessem ser estimulados por uma decisão social favorável.

Do ponto de vista da oralidade tem sido reconhecida de há muito a influência lingüisticamente unificante dos grandes centros urbanos sobre sua periferia, cuja extensão varia com o vigor social do centro. Desse modo, não seria de estranhar que em redor de cidades como Belém, Recife, Salvador, Rio de Janeiro, São Paulo, Porto Alegre, Brasília e tantas mais se formassem grandes unidades faladas tendencialmente unificadas mas tendencialmente diferenciadas entre si. Essa unificação focal com eventual diferenciação interfocal é acompanhada por um processo de audição de massa, pelo rádio, pela televisão, em que coexistem padrőes diferentes de oralidade, mas que, quaisquer que sejam suas nature- 
zas segmentares, tendem a ter influência de âmbito nacional: as tendências unificadoras, assim, coexistiriam com tendências diferenciadoras, ensejando, acaso, unidades nas variedades de um tipo mais alto. Para observadores obsessivos da minha idade, a elocução profissional no rádio, primeiro, e no rádio e televisão, agora, sem falarmos do teatro e do cinema, tem ido - quando não se imponha tipização dialetal horizontal ou vertical - tem ido, repito, em pós de um padrão nacional unificante (mas não uniformizante), em que alguns vêem o poder do "imperialismo" flúmino-paulista. Creio que se pode reputar altamente satisfatório esse padrão, pois parece altamente aceito pela grande maioria dos ouvintes. Excluo, de novo, de consideração os usos segmentares, mais do que necessários, quando se trata de documentar qualquer recanto do país com gente desse recanto, de qualquer estrato social ou de gente desse estrato etc.

A modalidade escrita, porém, apresenta-se de forma aparentemente mais contraditória. Leva-se em conta, primeiro, o fato de que "no passado" se escrevia mais correta e mais unificada e mais uniformemente - o que, para o "passado" do nosso realismoparnasianismo, não parece ser impressão falsa. Observa-se, com freqüência, que há indivíduos falantes com padrơes cultos apreendidos pela mera via da audição (e a contraprova é, em tais casos, a impotência desses indivíduos de se fazerem escreventes...). Existe também a má prova, a dos indivíduos com forte capacidade escritora, mas corn fraca capacidade falante (por timidez, medo, inexperiência, isolamento, por não terem tido aprendizado específico, por idealizarem a expressão oral a ponto de inibição etc.). Seja como for, parece mais fácil falar "bem" que escrever "bem".

Em verdade, a primeira barreira que se tem de vencer, quando se cogite de escrever "bem", é o preconceito de que existe "uma gramática do correto para todos os fins". No momento em que cada escritor criador, no plano da ficção ou da poesia, quer atingir a genuinidade de um pensamento nascente verbalmente errante ou de uma enunciação viva de emaranhados de estratos culturais e estados emocionais díspares, a partir desse momento é impossível pensar numa gramática do correto apriorístico, porque corretas serão aquelas "incorreçðes" que verdadeiramente reflitam as linguagens dos estratos e dos estados.

A partir daí, inaugura-se o usuário da modalidade escrita que pode dar a ela a feição do seu objetivo: Guimarães Rosa de Grande Sertão: veredas também sabia fazer ofícios e relatórios diplomáticos com respeito das chamadas regras gramaticais (em verdade, ele tinha tal domínio da canônica gramatical normalizada e codificada como camisa-de-força que, ao infringi-la, o fazia com total conhecimento criador: escrevia bem o errado, porque sabia melhor o certo) (essa frase aí minha deve ter pares de aspas em cada

A LINGUAGEM OFICIAL

sim, das línguas de cultura que haja do mundo moderno exige, asmodalidade escrita: o pólo da ficcã̃a dois pólos na pragmática da obrigatório que o faça) assumir todos os capria, que pode (não é bais e gramaticais d criatichos e arbítrios verna verdade ñ̃ 
sem sequer ser lúdico - grau zero final da escritura); o outro é o pólo da inequivocidade, que idealmente se atingiria na linguagem da lógica matemática, das ciências naturais e, já quase nunca, das ciências sociais - e que, idealmente, é também o pólo da linguagem oficial.

A linguagem oficial é a linguagem do Estado e seus prepostos, ou, por extensão, dos aparelhos e instituições que, com vida própria, se põem a serviço de certas verdades ou "verdades", religiosas, éticas, pias, assistenciais, e a de seus servidores.

A linguagem oficial - por comodidade, por eficácia, por simbolística - apresenta caracteres formais mais ou menos tradicionalizados: é sabido, por exemplo, que a linguagem cartorial da Justiça e do Direito é, a um tempo, arcaizante, prolixa, não raro redundante, porque de certo modo é ritual; é sabido que a linguagem escrita das leis, decretos, despachos, decisões administrativas, discursos, proclamações, visa, teoricamente, ao claro e inequívoco - em momentos de coragem cívica e estatal - e, à socapa, ao equívoco ou à ambigüidade, em momentos de arrocho, mas sempre com pompa e circunstância, mesmo nos Estados democráticos.

Enquanto houver Estado, é de crer que a linguagem oficial buscará realizar seu ideal de universalidade com coerção - esclareçamos, buscará dizer de tal modo que os que o queiram possam entendê-la (se preparados colegial e culturalmente para tanto) e os que não o queiram não possam alegar razões para isso, graças ao fato de que os recursos gramaticais e verbais postos a seu uso são os codificados sob a rubrica de normativos, normais e, por isso, corretos. É mesmo de crer que o tendencial social unificante das ciências e da ajuda mútua e do convívio pacífico buscará sempre exprimir-se pela norma, graças ao que inversamente o tendencial social utópico, lúdico, expressivo, artístico, possa valorizar-se pela antinorma, pela fratura, pelo "erro".

Advoga-se, assim, a tese de que os fins determinam a feição específica que como meio a língua deve assumir (mesmo quando o fim seja a língua mesma e o meio seja a mesma língua). E nisso advoga-se a tese de que deve haver uma gramática lou gramáticas) e um léxico (ou léxicos) canônicos, que digam o que é e o que não é regular, o que é ou o que não é empregável na linguagem oficial (uma de cujas regras de ouro do uso será o de já ter sido empregado).

Postula-se, assim, uma norma literária (isto é, letrada, literatada, escrita, em suma) culta - porque, para assenhorear-se dela, o indivíduo escrevente a fica aprendendo (e desaprendendo-a para reaprendê-la) enquanto viva lúcido.

Entre os dois pólos, portanto, há uma imensa massa intermédia de todos os matizes e para todos os fins canônicos e não canônicos ou semicanônicos ou incanônicos ou acanônicos.

Isso parece ser assim com todas as línguas de cultura. Sendo-o, porque não o seria para com a nossa?

A NORMALIZAÇÃO E A CODIFICAÇ̃̃O DA NORMA - 
tema, norma, subnorma, subsistema, dialetos. Mas devemos ater-nos ao fato de que os indivíduos falantes e escreventes no geral automatizam o sistema relativamente cedo (pelos treze-quinze anos), vale dizer, não têm consciência de seu uso e não entendem o seu não uso. Mas a norma, que emerge dos usos do sistema no que eles tenham de mais freqüente, em se tratando de uma língua culta, quer dizer, com tradição-transmissão escrita, de tal modo que nos seus escritos passados o passado esteja presente no presente, a norma culta pede estudo do passado para poder estar presente e ser usada no presente. Assim, pojs, não parece que se devesse lutar contra a norma comum culta de uma língua comum de cultura. Haveria, apenas, que contra-regrar o que há realmente como normal para o âmbito do português como um todo; o que há realmente como normal para cada variedade nacional do português (duas das quais, neste momento da história, perfeitamente caracterizáveis, a norma nacional portuguesa, a norma nacional brasileira). Porque, de fato, os impedimentos, na linguagem oficial, para que se possa atingir essa norma destituída de cerebrinices e bizantinices são de vária natureza:

a) a normalização oferecida pelas nossas gramáticas correntes tem vergonha de encampar como realidades cultas normais uma quantidade de práticas e pragmáticas linguageiras universalizadas entre nós, fatos esses cuja não observância constitui um ato de força permanente do escritor oficial ou usuário da linguagem oficial contra si mesmo;

b) a normalização oferecida pelas nossas gramáticas, ademais de suas cerebrinices ou bizantinices, é uma normalização "culta", isto é, que encerra passado no presente, encerrando assim mais de uma potencialidade "regular"; seu aprendizado não é nem pode ser espontâneo (como o da língua falada no nível do vernáculo - a que é aprendida em casa e de uso em casa para os fins de casa), impondo-se seu estudo atento e cuidado por longos anos e a manutenção do conquistado por mais longos anos, já então como que espontâneo "de segunda natureza", a valer tanto quanto a primeira natureza que, no indivíduo, em nã́o mais havendo, não se sabe como ora seria: o adquirido como segunda natureza pode funcionar - e na imensa maioria dos casos funciona como "espontâneo" por ter sido (vá lá o termo) automatizado;

c) a normalização oferecida, mesmo despojada de cerebrinices, não está tendo ensino institucionalizado à altura das necessidades sociais - e isso parece claramente espelhar-se na forma por que, na modernidade, a linguagem oficial se vem alterando, perdendo a clareza das articulações mesmo convencionais ou tradicionais, obscurecendo-se no uso aparentemente personalizado da pontuação, vacilando na ortografia, fazendo-se difusa na semântica, não sabendo evitar as ambigüidades - e quanto mais se poderia dizer.

$\mathrm{Na}$ verdade, esses aspectos são passiveis de correção em âmbito nacional, desde que a sociedade, através do Estado ou de comissionados pelo Estado, gere instrumentos consabidos - vocabulários ortográficos, onomásticos, terminológicos, dicionário de autoridades para o cerne do léxico oficial $(50$ mil palavras das 400 mil averbáveis [de fato averbadas no próximo Vocabulário 
ortográfico da língua portuguesa, da Academia Brasileira de Letras] - , com o máximo de conexões possíveis, sinonímicas, antanonímicas, paronímicas, ideológico-analógicas etc. etc. etc.), uma gramática explícita quanto às inovações ou manutenções brasileiras universalizadas em nível culto e - sobretudo, sobretudo - um magistério qualificado em sua formação e não degradado no exercício de sua profissão, graças ao que os alunos pudessem, durante dez-catorze anos, ter duas horas, em cada um de cinco dias úteis da semana, de estudo, leitura, redação, que transformassem a angústia presente, de uma assimilação mecânica, em convívio criativo com a língua - essa marca de humanidade e humanização que é a própria língua. 


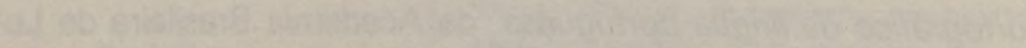

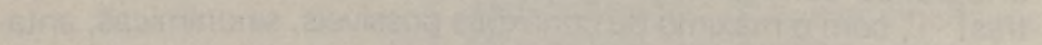

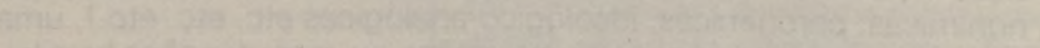

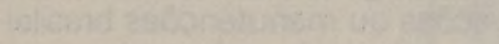

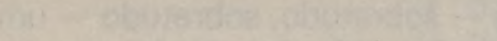

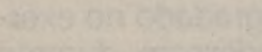

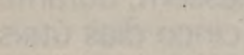

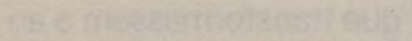

W

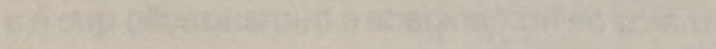

$\cdot$ 